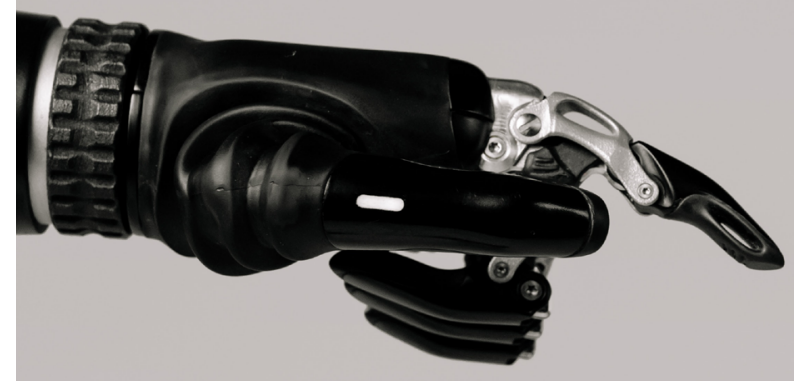

DOI: 10.5380/2238-0701.2021n22.12

Data de Recebimento: 20/05/2020

Data de Aprovação: 19/03/2021

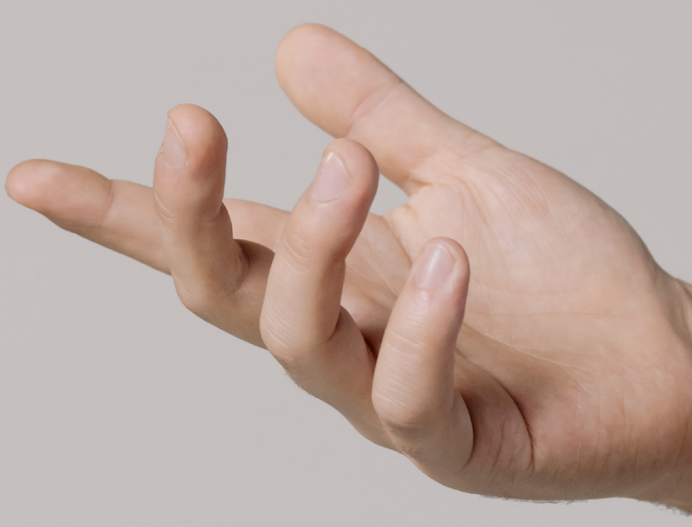


Figuras Pós-Humanas e Inteligência Artificial: uma reflexão a partir de Black Mirror 


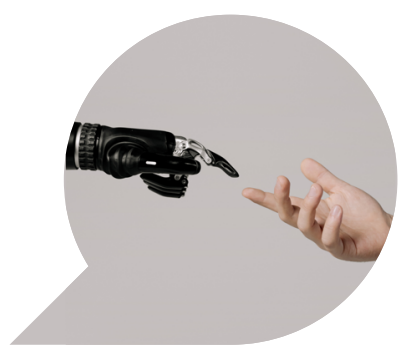

\title{
Figuras Pós-Humanas e Inteligência Artificial: uma reflexão a partir de Black Mirror
}

\author{
Post-Human Figures and Artificial Intelligence: \\ a reflection from the Black Mirror
}

Cifras Poshumanas e Inteligencia Artificial: un reflejo del Black Mirror

BRUNA COUTINHO SILVA

FABIANO VELIQ ${ }^{2}$

Resumo: $O$ presente trabalho tem como objetivo discutir sobre as figuras pós-humanas que emergem no cenário atual da realidade social e da ficção científica. Para tanto, iniciamos apresentando o declínio do projeto humanista da modernidade, para, desse modo, estabelecer o contexto da emergência do pós-humanismo. Posteriormente, tratamos da conceituação sobre tais figuras pós-humanas, especificamente, os androides e os ciborgues, seguida da explanação sobre a Inteligência Artificial (IA). Após a discussão teórica, e em conexão com a mesma, empreendemos a análise do episódio "Be right back", de Black Mirror. A relevância da temática nos tempos atuais reside em as reflexões científicas acompanharem

1 Doutoranda em Psicologia pelo Programa de Pós-graduação em Psicologia, pós-graduada em Filosofia Contemporânea e graduada em Psicologia, pela PUC Minas.

2 Doutor em Psicanálise pela PUC Minas. Mestre em Filosofia da Religião pela Faculdade Jesuíta de Belo Horizonte - FAJE, Especialista em Teologia Sistemática pela Faculdade Batista de Belo Horizonte, Graduado em Filosofia pela UFMG. Atualmente é doutorando em Filosofia na UFMG e professor do departamento de Filosofia da PUC Minas. 
as produções tecnológicas que vêm colocando em questão o entendimento sobre o que é ou não humano e "borrando" cada vez mais essas fronteiras.

Palavras-chave: pós-humano; inteligência artificial; Black Mirror.

Abstract: The present work aims to discuss the post-human figures that emerge in the current scenario of social reality and science fiction. To do so, we begin by presenting the decline of the humanistic project of modernity, in order to establish the context of the emergence of post-humanism. Subsequently, we deal with the conceptualization of such posthuman figures, specifically androids and cyborgs, followed by an explanation of Artificial Intelligence (Al). After the theoretical discussion, and in connection with the same, we undertook the analysis of the episode "Be right back", Black Mirror. The relevance of the subject in the present times lies in the scientific reflections accompanying the technological productions that have been questioning the understanding of what is human or not and increasingly "blurring" these frontiers.

Keywords: post-human; artificial intelligence; Black Mirror.

RESUMEN: Este artículo tiene como objetivo discutir las figuras poshumanas que emergen en el escenario actual de la realidad social y la ciencia ficción. Con este fin, comenzamos presentando el declive del proyecto humanista de modernidad, a fin de establecer el contexto del surgimiento del posthumanismo. Posteriormente, nos ocupamos de la conceptualización de tales figuras posthumanas, específicamente, los androides y los cyborgs, seguidos de una explicación de la Inteligencia Artificial (IA). Después de la discusión teórica, y en conexión con ella, emprendimos el análisis del episodio "Vuelvo enseguida", de Black Mirror. La relevancia del tema en los tiempos actuales radica en las reflexiones científicas que acompañan a las producciones tecnológicas que han cuestionado la comprensión de lo que es y lo que no es humano y "difumina" estas fronteras cada vez más.

Palabras-clave: post-humano; inteligencia artificial; Black Mirror. 


\section{O declínio do projeto humanista da modernidade}

A modernidade pode ser compreendida como um processo histórico, cultural, político, filosófico e social, que partiu da experiência ocidental e europeia, podendo ser situado desde o século XV, a partir das grandes navegações; passando pelo Renascimento e o Humanismo, no século XVI, ao lado da Reforma Protestante; e da revolução científica, no século XVII, conforme Marcondes (2008). Seu projeto incluiu o progresso da humanidade a partir do novo, a partir do desenvolvimento da razão, do Estado e da economia capitalista, aliado ao antropocentrismo, ao individualismo e à propriedade privada.

O projeto da modernidade pode ser compreendido como uma busca pela plena realização da humanidade do homem como via de consolidação de uma sociedade justa (SAFATLE, 2009). Esse projeto persiste no imaginário social, tanto que "[...] sentimo-nos seguros ao reencontrar a imagem identitária do homem, a ponto de imaginar que a ausência de tal imagem só poderia gerar o caos e a deposição de todo projeto de racionalização social” (SAFATLE, 2009, p. 201).

A sustentação da figura do homem, portanto, cumpriu e cumpre um papel sociopolítico e identitário nas diversas sociedades humanas. Para Safatle (2009), a figura do homem se sustenta em três pilares que caracterizam sua humanidade: 1) autonomia: capacidade de autogoverno, de definição das próprias normas; 2) autenticidade: expressão de uma interioridade singular e insubstituível; e 3) unidade reflexiva: capacidade de integrar experiências e representações em um espectro conscientemente entendido como uma identidade. Esse homem forjado na modernidade, não por acaso, possui os mesmos atributos de Deus, um claro resquício da moralidade cristã como horizonte regulador (SAFATLE, 2009).

Safatle (2009) se questiona sobre o que fica de fora dessa imagem de homem, desse modo universalizante de o pensar - resta a instabilidade, o caos. O projeto persiste, portanto, pois é terapêutico; certa normatividade padronizada nos conforta. Nesse sentido, o inumano seria tudo que está fora do escopo do humano ${ }^{3}$. Se opõe ao humano por

\footnotetext{
3 Reza Negarestani propõe uma nova forma de pensar esse "inumano" em seu livro "o trabalho do inumano" (2021) em que considera as questões vinculadas a IA e propõe um alargamento da noção de "humano" como uma demanda atual e necessária para dar conta das mudanças tecnológicas. Segundo Negarestani: "Nós devemos encaminhar uma solução para o problema do que significa ser humano e, por meio dessa exploração, reconstruir e reformular o humano" (NEGARESTANI, 2020 p. 68).
} 
suas características de animalidade (falta de controle), impessoalidade (não identificação com um eu) e monstruosidade (não cabe na forma humana; irregular; amorfo) (CICERO, 2009).

No entanto, a razão como princípio garantidor da liberdade e da autonomia humana no projeto iluminista, razão que se fundamenta no raciocínio lógico e que se volta para a produção de técnicas e ciência, foi ela própria sua ruína. O imperialismo predatório pautado na ideologia da civilização levou às grandes guerras e aos conflitos geopolíticos irresolúveis geradores da temida "barbárie".

Política neoliberal, globalização, tecnologias de informação, ideologia do consumo são todos fatores de expansão do capitalismo na transição do último ao atual século, marcados por muita violência (haja vista as grandes guerras), acompanhado do crescimento das mídias de comunicação e da mundialização do capitalismo financeiro. Como processos correlatos, há que se pensar os impactos na constituição de modos de relações entre humanos, outras espécies e tecnologias pautadas em interesses elitistas, que se fazem valer "a qualquer custo". Para Santaella (2010, p.118), parafraseando Luttwak, seria o turbo-capitalismo que vivenciamos: "[...] uma mudança estrutural acelerada que produz mais criação e mais destruição, mais eficiência e mais desigualdade, e que calorosamente acolhe as máquinas de guerra, as mais lucrativas do globo".

Portanto, no século XX, as produções tecnológicas cada vez mais se complexificam e servem a diferentes interesses e propósitos, e é nesse contexto que emerge a discussão acerca do "pós-humano".

\section{O pós-humanismo como consequência do avanço tecnológico}

Como vimos, com o desenvolvimento do modo de produção capitalista, alinhado às múltiplas criações tecnológicas, assistimos uma transição também paradigmática. A morte do homem representa a morte da metafísica moderna (CICERO, 2009). O cenário pós-moderno, desse modo, engloba diferentes perspectivas sobre o mundo, sobre o ser humano, sobre a vida. Na esteira desse processo de transformações nos modos de ser e viver humanos, encontra-se a discussão sobre o pós-humano. 
Nos fins da década de 1980, mais fortemente ao largo da década de 1990, as terminologias sobre o pós-humano - pós-biológico, pós-evolucionista, ciborgue, bio-maquínico - começaram a ganhar espaço no cenário científico e artístico, europeu (França, Itália) e estadunidense. Destaca-se nesse cenário inicial Robert Pepperell, artista inglês, que utiliza a nomenclatura pós-humano:

[...] para se referir tanto à derrocada do humanismo tradicional para dar conta das transformações por que o humano está passando quanto às fontes principais dessas transformações que se encontram na convergência do humano com as tecnologias, tais como: comunicação global, realidade virtual, protética, nanotecnologia, redes neurais, algoritmos genéticos, manipulação genética e vida artificial (SANTAELLA, 2010, p.101).

Já é perceptível como a nomenclatura pós-humano congrega diversos tipos de tecnologias, as quais se encontram em estrita relação com interesses humanos: de comunicação, de autoconhecimento, de expansão das fronteiras corporais, de produção (enquanto artifício) de vidas.

Para Marchesini (2010), há uma grande potência na hibridação do humano com o não humano. As alteridades não humanas - animais, robôs, por exemplo - cujas capacidades de cognição e reciprocidade dialógica começaram a ser investigadas no século XX, confrontaram a tese do antropocentrismo e do solipsismo, ou seja, a referência antropológica de que o homem, cuja essência é pura, embora incompleta, e sua experiência de vida estão no centro de seu próprio desenvolvimento, e que tudo mais orbita em torno disto.

A perspectiva pós-humanística não é sinônimo da superação da condição humana ou de nossa obsolescência, e sim é inclusiva aos não humanos na nossa constituição. "A alteridade não humana na perspectiva pós-humanística é, ao contrário, uma entidade dialógica capaz de operar deslocamentos na dimensão humana" (MARCHESINI, 2010, p.179).

Desde os primórdios da existência da espécie humana, estamos a testar os limites normativos de nossa "natureza", de modo a nos reinventar e produzir outros modos de ação no mundo. A atividade humana resulta de uma profunda interação entre recursos internos e recursos externos, ao ponto de não conseguirmos determinar exatamente as fronteiras de cada um. Podemos observar isto na relação entre um músico e seu instrumento, por exemplo. Ambos acabam formando o que 
Kaptelinin (apud LEFFA, 2009) denomina "órgão funcional”. "Um órgão funcional surge quando qualquer recurso interno do nosso organismo associa-se intimamente a um determinado instrumento externo para executar uma mesma tarefa de modo integrado" (LEFFA, 2009, s.p.). Além dos instrumentos ampliarem as funções dos órgãos do corpo humano e das funções mentais superiores, diversificando-as, a eficiência também aumenta e novas funções são criadas, sempre de modo processual e dialético. "Na base da proposta do órgão funcional está a ideia de que essencialmente não somos nem apenas máquinas, nem apenas pessoas. Somos pessoas e máquinas" (LEFFA, 2009, s.p.).

Na medida em que vamos constituindo uma relação de maior proximidade com as máquinas, vamos as tomando como dotadas de certa identidade, promovendo processos de interação mutuamente afetáveis e transformativos.

Quando se produz um texto no computador, por exemplo, seja um e-mail, um relatório, ou este próprio texto que estou escrevendo agora, há uma interferência constante da máquina, alinhando as palavras na página, sugerindo correções, disponibilizando sinônimos, etc. A autoria do texto perde-se entre o homem e a máquina (LEFFA, 2009, s.p.).

Para Leffa (2009), e já buscando tecer uma conexão com o próximo tópico de discussão, sobre os ciborgues, a ciborguização ocorre no processo interacional entre órgãos do corpo/funções mentais superiores com os artefatos culturais. Desse modo, Leffa (2009) afirma que a tecnologia pode humanizar, além de desumanizar, como sugerem algumas ficções e mesmo leituras teóricas do pós-humano, na medida em que promove modos de existir antes impossíveis. Basta pensarmos no caso do cientista Stephen Hawking. "Os instrumentos são capazes de transformar o sujeito, mas não de substituí-lo; haverá sempre uma reserva de domínio que constitui o sujeito, por mais cindido e fragmentado que ele possa ser" (LEFFA, 2009, s.p.). Essa faísca de sujeito persiste e é o elo da hibridação humano-maquínica, como veremos a seguir. 


\section{Androides e ciborgues como materializações pós-humanas}

No que diz respeito aos androides, sua origem terminológica data do século XVIII e é atribuída aos enciclopedistas Diderot e D'Alambert, que os definem como autômatos com aparência humana (MACIEL, 2007).

$\mathrm{O}$ androide se diferencia do ciborgue em razão de sua origem inteiramente artificial, e se diferencia dos robôs pelo seu nível de complexidade, tanto física (sua aparência extremamente humanizada, através da reprodução da organicidade) quanto emocionalmente (OLIVEIRA, 2003). Em relação a este aspecto, pode-se observar frequentemente na ficção literária ou cinematográfica como os androides possuem razoável autonomia cognitiva e emocional. Razoável, por ora, sobre os androides existentes no mundo real, uma vez que são criados a partir de um background de competências e habilidades previamente definidas.

A figura do ciborgue, por sua vez, inicialmente, remete aos experimentos laboratoriais, biotecnológicos, que começaram a se expandir em meados do século XX. Na década de 1960, em Nova York (EUA), foi criado o primeiro ciborgue, um rato em que foi implantado uma bomba que injetava produtos químicos em seu corpo, alterando seu funcionamento fisiológico. Os cientistas envolvidos no empreendimento imaginavam algo muito além do espaço do laboratório: interessava-Ihes produzir um humano ampliado - expressão que define cyborg ou cybernetic organism - que melhor se adaptasse a viagens astronáuticas, controlado por substâncias como energia nuclear (KUNZRU, 2009). A origem do termo também é associada a Clynes e Kline, cientistas da área de psiquiatria, psicofarmacologia e neurociências, na década de 1960, "[...] para designar os sistemas homem-máquina autorregulativos, quando ambos aplicavam a teoria do controle cibernético aos problemas que as viagens espaciais impingem sobre a neurofisiologia do corpo humano" (SANTAELLA, 2003, p. 185).

Haraway (2011) afirma que somos todos ciborgues, o que pode ser interpretado, segundo Santaella (2003), de modo literal, uma vez que nossos corpos estão se tornando híbridos com as tecnologias biológicas e informacionais, e metaforicamente, por representar uma transição cultural da sociedade industrial à era informacional.

De acordo com Kunzru (2009, p. 122), o ciborgue "era uma espécie de sonho científico e militar". A expectativa de expansão das fronteiras 
humanas se mostrou muito forte nas forças militares e nas produções médicas ocidentais. O denominador em comum seria o aprimoramento humano. Braços robóticos, exoesqueletos, marca-passos, programação genética - são exemplos de biotecnologias que se inserem naquele escopo. "Existe, agora, a possibilidade de se fabricar humanos melhores, ampliando suas capacidades por meio de dispositivos artificiais" (KUNZRU, 2009, p. 122).

Conforme Kunzru (2009), de modo diferente, mas embasado em uma compreensão sistêmica das máquinas, em 1948, Wiener, engenheiro, elaborou a teoria do feedback, a partir da qual compreendia que o funcionamento de sistemas que têm alguma finalidade, por exemplo, a regulação da temperatura em uma máquina industrial, depende de um circuito de retroalimentação de informações. Wiener denominou seu campo de estudos e produções teóricas de Cibernética, palavra de origem grega, kybernetes, designando "homem que dirige". Sua teoria foi pensada para administrar sistemas complexos, tendo como substrato esse fluxo informacional permanente, que funciona por percepções, ações e feedbacks. "Os seguidores de Wiener viram a cibernética como uma ciência que explicaria o mundo como um conjunto de sistemas de feedback, permitindo o controle racional de corpos, máquinas, fábricas, comunidades e praticamente qualquer outra coisa" (KUNZRU, 2009, p.124).

As ideias de Wiener fundamentaram práticas de produção de ciborgues, e a compreensão de humano cada vez mais se aproxima de um sistema de redes de informações adaptativas e conectáveis umas às outras. Entretanto, foi uma teoria que caiu em desuso, sobretudo devido à crítica de que os sistemas biológicos, humanos e sociais não são comparáveis. Dois ruídos da cibernética, porém, permaneceram, de acordo com Kunzru (2009, p.126): o primeiro é a ideia do mundo como conjunto de redes e o segundo é a ideia "[...] de que não existe uma distinção tão clara entre pessoas e máquinas quanto alguns gostariam de crer".

Segundo Tomas (apud SANTAELLA, 2003), Wiener concebia o século XX como a era da comunicação e do controle, sendo os sistemas maquínicos e os organismos vivos funcionalmente equiparados, uma vez que ambos se organizam como redes que produzem, reproduzem e transmitem informações. 
A partir da década de 1970, houve uma popularização dos androides e ciborgues via produções cinematográficas ${ }^{4}$, que exploraram fortemente a temática, envolvendo, geralmente, tramas complexas de subversão às hierarquias sociais. Se as tradições literária e cinematográfica, por um lado, apresentavam a figura do androide/ciborgue ainda de modo muito binário, destacando claramente a oposição entre homens e máquinas, por outro lado, ou, simultaneamente, certas produções como The Matrix, The Lawnmower Man e Blade Runner, destacam um fluxo informacional entre máquinas, homens, avatares, que os mistura a ponto de ser difícil estabelecer limites claros entre onde está a vida, a consciência, o corpo dessas entidades (SANTAELLA, 2003).

O ciborgue é ficção e realidade social, simultaneamente; aparece na literatura e no cinema ao mesmo tempo em que se expressa no mundo político e relacional. Haraway (2011) se interessa mais pelos "frutíferos acoplamentos" (p. 37) que podem decorrer do ciborgue do que por uma leitura biopolítica (crítica ao conceito foucaultiano), o que ela denomina "política ciborgue" (p. 37).

Ao ciborgue não se aplica nenhuma narrativa de origem, ou mito originário, e por isto se opõe ao marxismo e à psicanálise, bem como ao humanismo. Toda origem convoca a noção de unidade, núcleo, e o ciborgue subverte tal lógica. Ele não espera ser salvo por uma conciliação unitária e totalizante: a família, o Estado, o capital, o/a parceiro/a, o grupo social, o inimigo. A razão de ser do ciborgue é sua hibridação. "Com o ciborgue, a natureza e a cultura são reestruturadas: uma não pode mais ser o objeto de apropriação ou de incorporação pela outra" (HARAWAY, 2011, p. 39).

Para Haraway (2011), falar da emergência de uma política ciborgue pressupõe, antes, três grandes rupturas de fronteiras entre: animal/humano; humano/maquínico; e físico/não físico.

Sobre a primeira, Haraway declara:

Na cultura científica estadunidense do final do século XX, a fronteira entre o humano e o animal está completamente rompida. Caíram as últimas fortalezas da defesa do privilégio da singularidade [humana] - a linguagem, o uso de instrumentos, o comportamento social, os ventos mentais; nada disso estabelece, realmente, de forma convincente, a separação entre o homem e o animal (HARAWAY, 2011, p. 40).

4 Aos leitores interessados em conhecer as diversas expressões artísticas que discutem o pós-humano, ver Santaella (2003), que dedica o livro inteiramente à temática. 
Nesta fala de Haraway ficam claras as muitas similitudes entre os homens e os animais, sobretudo com a classe dos Mamíferos, de modo que não há como precisar certamente até que ponto somos seres da "natureza" ou seres da "cultura".

Sobre a segunda, Haraway afirma que o desenvolvimento tecnológico principiado no século XX permitiu que as fronteiras entre homens e máquinas se borrassem. "Nossas máquinas são perturbadoramente vivas e nós mesmos assustadoramente inertes" (HARAWAY, 2011, p. 42).

Por fim, a terceira grande ruptura trata da imprecisão entre as fronteiras física e não física, inaugurada também no século XX pela teoria quântica, que trata dos princípios da instabilidade, da ruptura da lógica causal entre espaço, tempo e acontecimento, da complexidade. As redes tornaram-se ubíquas; as máquinas se virtualizaram e fluem; as tecnologias se tornam cada vez mais menores e portáteis - inclusive, acopladas no próprio corpo.

Nesse caminho é que se discute também o surgimento da inteligência artificial, como tecnologia cada vez mais presente no cotidiano da vida humana e que está configurando outros modos de relações e fazendo emergir novas problemáticas.

\section{A noção de inteligência artificial}

No campo das ciências da informação, encontramos recorrentemente a proposta de categorização das definições de inteligência artificial proposta por Russell e Norvig (2013). Estes autores colocam que há inúmeras definições para inteligência artificial, que remetem a computadores ou máquinas capazes de realizar com fidelidade ou sucesso certas atividades humanas (desempenho humano), e capazes de pensar e de raciocinar (racionalidade). Os componentes "pensamento" e "ação" em sua expressão de semelhança com as competências humanas são centrais para compreendermos o sentido da IA, enquanto campo de estudo e de aplicação.

Sobre a origem do termo, Camargo (2014) coloca:

A inteligência artificial $(I A)$ é inteligência dos agentes artificiais assim como o campo do seu estudo acadêmico. O termo foi introduzido em 1956 como título da conferência Dartmouth Summer Research Project 
on Artificial Intelligence organizada por John McCarthy. A nova disciplina baseia-se na conjectura de que qualquer aspecto da inteligência humana, da linguagem ao uso de conceitos e abstrações, poderia ser descrito de maneira tão exata que uma máquina deveria ser capaz de reproduzi-lo (CAMARGO, 2014, p. 164).

Um estudo marcante no campo da IA foi realizado e publicado por Alan Turing na década de 1950. O Teste de Turing, cuja inspiração era o "jogo da imitação". Neste jogo, havia três participantes: A, B e C; um homem, uma mulher e um interrogador, respectivamente. O objetivo deste jogo era que o interrogador descobrisse quem era o respondente, se homem ou mulher, sendo as interrogações mediadas por um chat. No teste proposto por Turing, um computador simularia A ou B, e o interlocutor deveria descobrir qual dos dois era a máquina (GUNKEL, 2017).

Consequentemente, se um computador de fato pode se tornar capaz de simular um ser humano de ambos os gêneros, em intercâmbios comunicativos com um interrogador humano de modo que o interrogador não consiga dizer se está interagindo com uma máquina ou outro ser humano, Turing conclui que essas máquinas devem ser consideradas "inteligentes" (GUNKEL, 2017, p. 7).

A pergunta que movia Turing era se as máquinas seriam capazes de pensar. Supostamente, consideramos a razão, cognição ou inteligência como o grande diferencial humano frente às outras espécies animais. No entanto, para Cappucci (2010), a capacidade simbólica é mais fácil de ser simulada que a corporeidade humana. A justificativa para isso, segundo o autor, é dada por Moravec. As capacidades de percepção e interação com o ambiente e a sensorialidade humanas são muito mais primitivas, comuns a todos os seres viventes, ao passo que a capacidade simbólica na história do homem é muito mais recente. Nesse sentido “[...] 'raciocinar' é mais fácil que 'perceber' [...] porque o pensamento racional é muito mais 'jovem' e menos complexo, então é mais fácil de simular nas (de transmitir às) máquinas" (CAPUCCI, 2010, p. 261).

A simulação de modo a se alcançar cada vez mais a expressão da realidade mesma é um movimento artístico antigo, que data do Renascimento, onde nasce a perspectiva e as tentativas de produções mais próximas à realidade. Essa tendência se inicia nas pinturas e esculturas, passa pelas fotografias, pelo cinema até a realidade virtual (CAPUCCI, 2010). 
Quando se trata da busca humana por estender suas competências por meio das máquinas e via simulação, Capucci (2010) coloca que o corpo assume uma centralidade indispensável. Seu pressuposto é de que mente e corpo estão interconectados e em relação de interdependência, e as tecnologias de interface hão de perpassar sobre a cognição e também a sensibilidade. Nesse sentido, faz um contraponto entre a IA e a robótica. Enquanto a primeira partiu da simulação da competência humana simbólica para depois agregar o corpo (membros), a segunda partiu do corpo e o foi complexificando ao associar ao mesmo "[...] capacidades perceptivas, motoras, dinâmicas e computacionais, integrando-os ainda a sistemas baseados na inteligência artificial" (CAPUCCI, 2010, p. 259).

Como vimos, o paradigma informacional é a chave de compreensão para esses processos de interface humano-maquínica em curso. Para Harari (2016), o movimento de centramento das ciências biológicas no século XXI no modelo de processamento de dados para explicar o funcionamento da vida pode se mostrar equivocado; decerto, é fruto desta época. No século XIX, por exemplo, a analogia com a máquina e o motor foi utilizada como paradigma em diversas ciências - o corpo era um conjunto de órgãos, que exerciam funções específicas, precisando de determinados estímulos e sofrendo tais e quais desgastes, tendo em vista a engenharia mecânica como fonte de avanços tecnológicos. Com o desenvolvimento de outras tecnologias no atual século, sobretudo, as ciências da informação, justifica-se pensar a vida e os seres vivos sob a ótica do processamento de dados.

Atualmente, a simulação do ser humano não apenas em suas competências e habilidades cognitivas, mas em relação ao seu comportamento e à sua aparência, evoluem cada vez mais com o desenvolvimento da robótica e das artes tridimensionais. Na década de 1970, Masahiro Mori, pesquisador japonês do campo da robótica, cunhou uma hipótese conhecida como The Uncanny Valley ou "O Vale da Estranheza", para descrever a reação dos seres humanos frente a outros seres cujas aparências são realisticamente mais humanas (MORI, 2012). A hipótese de Mori é que o desenvolvimento dos robôs (e mesmo personagens em animações ou jogos) progressivamente alcança mais familiaridade com a aparência humana, gerando o sentimento de empatia para com os mesmos. No entanto, tal familiaridade atinge um ponto crítico no qual não somos mais capazes de sentir empatia, mas, sim, estranhamento 
(ANDRADE et al., 2015; GRIMAUD, 2009; MORI, 2012; ROSA, 2018). O gráfico abaixo ilustra a hipótese de Mori, sendo que a resposta empática ou afinidade (linha vertical) varia conforme o nível de semelhança do objeto ou personagem com o ser humano (linha horizontal).

Figura 1 - Gráfico do Uncanny Valley

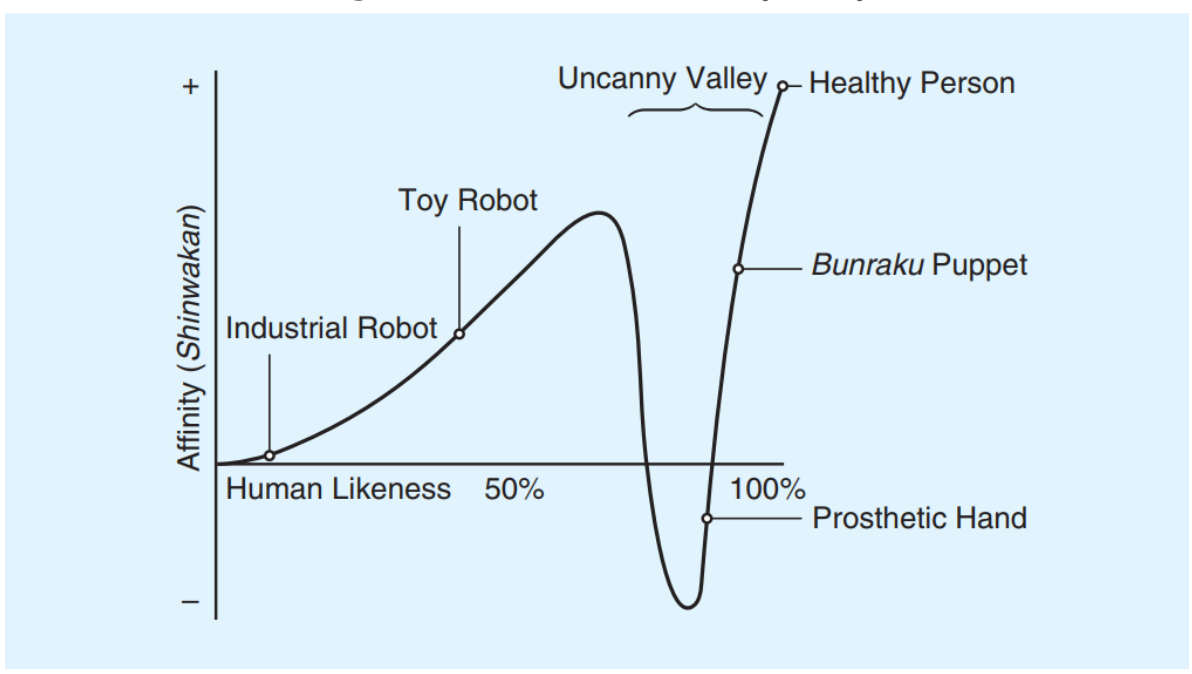

Fonte: MORI, 2012, p. 99.

A explicação para tal estranheza em MacDorman e Ishiguro (apud ROSA, 2018) é que o que encontramos em tais robôs humanoides, como os androides, é algo que não previmos, tendo em vista o modelo de pessoa e seus comportamentos. Rosa (2018) colabora com a discussão ao dizer que é próprio do ser humano agir de modo diferente, que não se encontra nas expectativas de outrem, e isso é fonte de estranheza também.

Isto significa que o que nos choca - a estranheza - não consiste na existência de uma grande diferença entre homens e robôs. Pelo contrário. Consiste antes numa semelhança demasiado grande, mas em que pequenas diferenças nos tornam o robô tão desconhecido quanto são para nós os outros homens (Dumouchel \& Damiano, 2016). Nessa medida, os robôs podem de facto assemelhar-se bastante a nós, humanos, tão semelhantes que eles nos são tão imprevisíveis e desconhecidos quando os outros homens também o são! (ROSA, 2018, p. 68). 
Certa expectativa humanista se mantém como horizonte de referência, quando tomamos os robôs humanoides como análise, o que irá aparecer adiante, quando trabalharmos com o episódio Be right back da série Black Mirror. É um paradoxo: queremos ver nas telas da televisão, do streaming e dos jogos seres cada vez mais parecidos conosco, mas, quanto mais o forem, mais os estranharemos e rechaçaremos.

\section{Sobre narrativas seriadas e metodologia de análise}

Dentre os modelos de ficção contemporâneos, as séries assumem lugar central quanto à quantidade de expectadores e de variedade narrativa. A ampla adesão cultural a esse modelo pode ser pensada a partir de sua capacidade universalizante e a humanidade com a qual os personagens são construídos, a fim de proporcionar maior realismo social e emocional, conforme destaca Azubel (2018). Azubel (2018), ainda, afirma que as séries televisivas e nos serviços de streaming materializam e corporificam o imaginário do nosso tempo.

Nesse sentido, Azambuja e Perri (2018) resgatam estudos sociológicos que apresentam como as mudanças tecnológicas, acentuadas pelo desenvolvimento capitalista, reconfiguraram nossa relação com as narrativas representacionais, no cinema, no jornalismo, na televisão.

\footnotetext{
Algumas inovações no conjunto de estímulos introduzido pela modernidade fez crescer a produção de jornais sensacionalistas, publicações de "instantâneos" de mortes de pedestres, parque de horrores e filmes com o máximo de tensão, tudo para proporcionar choques sensoriais cada vez mais intensos (AZAMBUJA; PERRI, 2018, p. 43).
}

Isso nos leva a pensar em como a série Black Mirror foi também pensada para chocar seu público. A série britânica estreou no ano de 2011 e foi criada por Charlie Brooker; sua originalidade gerou enorme projeção midiática. Frequentemente, é considerada uma distopia tecnológica, ou seja, uma narrativa que apresenta cenários completamente opostos a um mundo idealizado e justo, como nas utopias (ESTEVE, 2018). Nesse sentido, a série enfoca, especialmente, as relações entre os seres humanos e as tecnologias em cenários nos quais se está consolidado o modo de produção capitalista, alinhado ao desenvolvimento tecnológico incrementado nos mais infinitesimais espaços da vida humana. 
Black Mirror trabalha com a imbricação dos espaços ficcional e não-ficcional, na medida em que aponta uma série de relações e acontecimentos do presente, como aplicativos de relacionamento, entretenimento do estilo Big Brother, produções artísticas contemporâneas, relações amorosas mediadas por aplicativos, entre outros aspectos. Buonanno (2014), em entrevista acerca de narrativas midiáticas, reflete sobre os liames entre ficção e não-ficção, situando a distinção entre ambas, em última instância, na reivindicação da verdade. No entanto, são modos de narrar que podem estar imbricados em determinadas produções, sejam televisivas, sejam seriadas, ou mesmo na literatura.

Segundo Azambuja e Perri (2018), o produtor da série, Charlie Brooker, buscou influências de séries televisivas americanas dos anos 1960, com marcada influência de The Twilight Zone, criada por Rod Serling. "As histórias ambientavam situações sobrenaturais e inexplicáveis, tais como: viagens no tempo, mundos paralelos, aliens, fantasmas, vampiros e outros mistérios" (AZAMBUJA; PERRI, 2018, p. 43). Além disso, contém influências do gênero cyberpunk, que, para Amaral (2005), se trata de um estilo, definido em múltiplas facetas: comportamento e relacionamentos interpessoais (amor como algo disfuncional, vinculado mais a relações sexuais que ao romantismo; pluralidade de orientações sexuais; mundo governado por grandes corporações; cultura hacker como resistência; hibridação humano-maquínica); artes (Kabir Fernandez; Misery); cinema (Blade Runner, Freejack, Madmax, Minority Report, Robocop, The Matrix); drogas (uso constante, especialmente das que aceleram a mente, produzem relaxamento e/ou estados alterados de consciência, como ecstasy, LSD, anfetamina, cocaína, cogumelos); HQs (Akira, American cyborg, Ghost in the Shell); literatura (Isaac Asimov, com a série Foundation; William Gibson, com a trilogia Sprawl; Bruce Sterling, com a antologia Mirrorshades; Pat Cadigan; Neal Stephenson); ainda, com influências na moda, na música e na religião (AMARAL, 2005).

Tradicionalmente, a inserção de mídias audiovisuais em pesquisas se dá como estratégia de exemplificação de algum fenômeno e sua análise é realizada através do discurso obtido das mídias, a partir de descrição textual. A proposta de uma metodologia integrativa no campo da análise qualitativa de material audiovisual emerge do reconhecimento de que as imagens em si podem ser fonte de análise, e não apenas a descrição de suas cenas e tramas, como colocam Uchoa, Godoi e 
Mastella (2016). Nesse sentido, é possível desenvolver diferentes níveis de análise, associando elementos da materialidade audiovisual (cores, planos, estilos de filmagem) com a materialidade discursiva inerente à história narrada (personagens e suas relações) e à análise sociocultural (relações de poder, macroestrutura social, aspectos ideológicos).

Azubel (2018) constitui a metodologia de Análise Fílmico-Compreensiva da Narrativa Seriada (AFCNS), com base na Sociologia Compreensiva, sendo os pressupostos desta, no processo de análise: a crítica dos dualismos, entre razão e imaginação, sujeito e objeto; a recusa ao juízo de valor e ao pensamento maniqueísta; a sensibilidade de constituir uma leitura relativa, não unívoca, da realidade, em reconhecimento à complexidade e às possibilidades e limites de toda análise; a capacidade de pesquisar o estilo do cotidiano em seus múltiplos elementos, compostos também por gestuais, imaginários, para além das palavras. A AFCNS, sinteticamente, procede metodologicamente por decomposição e recomposição: a descrição dos episódios trabalhados, em termos de sua composição cênica e sequencial; e a sua recomposição em termos de sua síntese e análise.

Nossa proposta aqui é a combinação das duas metodologias de análise, contemplando a articulação com o referencial teórico.

\section{Eternizando humanos e simulando vidas em "Be right back"}

O episódio de Black Mirror, Be right back (BROOKER; HARRIS; REISZ, 2013), retrata a relação do jovem casal Martha e Ash. Por um acidente fortuito de carro, Martha perdera seu esposo, e passa a sofrer com essa perda irreparável. Quando descobre sua gravidez, e frente à grande solidão vivenciada, Martha é informada acerca de um serviço online de criação de um avatar de uma pessoa falecida, para interagir com pessoas próximas à mesma, solicitantes do serviço. Para concretizar tal avatar, a empresa faz busca na internet tudo o que o sujeito já disse online, qualquer coisa pública, nas redes sociais, e-mails etc. Quanto mais interações online o sujeito realizou, mais parecido se torna o avatar. Após criado, ele começa a se comunicar com mensagens; depois, com ligações. O último nível é a migração da IA para um corpo sintético, idêntico ao original. 
Martha hesitara antes de iniciar as interações online com o avatar de Ash. Nos momentos anteriores à sua decisão de aderir ao serviço, o episódio a mostra envolvida com tarefas de casa, como a limpeza, e seu trabalho com a pintura. Nessas cenas, a claridade toma conta, para fazer contraste com a escuridão das cenas nas quais ela retoma memórias de Ash, quando vai ao sótão e acha uma caixinha com fotos dele, ou quando está sozinha em casa, vivendo um luto silencioso, assim como a descoberta de sua gravidez.

A princípio, a ideia de interagir com um avatar the parece muito absurda, mas, à medida em que vai conversando com ele pelo chat, posteriormente, com chamada de voz, sua vida parece ganhar mais cor e interesse. Martha partilha com Ash detalhes de sua vida atual, sobre sua gravidez, sobre como tem se sentido, ao passo que Ash é cada vez mais interativo, com demonstrações de humor, carinho e preocupação. Essa humanização do androide é um aspecto que vai atravessar todo o episódio, como um ponto central que diz da nossa forma de sociabilidade apegada aos padrões humanistas.

Como se observa, no episódio tudo começa com a IA em interação virtual com o usuário, articulando-se progressivamente à sensibilidade, com a adição da voz de Ash, até se chegar na constituição do corpo sintético vinculado a essa IA que já vinha interagindo com Martha; processo de complexificação dos sistemas de IA apontador por Capucci (2010). Além disso, os componentes de "pensamento" e "ação", como centrais para uma experiência de IA mais completa do ponto de vista da robótica, conforme Russel e Norving (2013) estão presentes, muito embora, como veremos adiante, isso será um fator contestado pela trama do episódio, uma vez que, do ponto de vista de relações humanas afetivas satisfatórias com androides dotados de IA, capacidade de pensar e agir não são suficientes.

A revivescência de Ash por meio seu androide é insuficiente para Martha. Aos poucos ela vai se dando conta de que algo falta. $O$ jeito sempre solícito, perfeito e sem falhas do androide Ash; suas frases feitas e ações esperadas... essas atitudes incomodam Martha a tal ponto que chega a pensar em pedir ao androide se jogar no precipício; é o clímax do episódio. Quando ambos se encontraram na beira de um precipício, nesse momento crítico da relação, Martha se viu questionando qual o sentido de manter-se com um androide de seu esposo. "Você é apenas algumas ondulações de você. Você não tem história. Você é só 
uma atuação de algo que você fazia sem pensar, e isso não é suficiente" (BROOKER; HARRIS; REISZ, 2013). Essa "falta" tem relação não apenas com a noção de subjetividade enquanto manifestação singular, o que o androide não consegue manifestar, mas também com a concepção subjacente a todo o humanismo que é a alma, o ser humano como uma totalidade de corpo e alma, conforme Abbagnano (2007).

Como vimos anteriormente com Safatle (2009), a concepção de homem se assenta no pilar da autonomia, da autenticidade e da unidade reflexiva, atributos, respectivamente, vinculados à capacidade de ação própria, à expressão da singularidade e à manifestação de uma congruência conforme sua história e sua identidade - todos atributos que o androide de Ash não tinham e, justamente por isso, não o humanizaram o suficiente para que Martha pudesse "reviver" Ash. Esta figura amedronta e causa estranhamento. Cumpre evidenciar a expressão do Uncanny Valley (ANDRADE; VIEIRA; FIALHO, 2015; GRIMAUD, 2009; ROSA, 2018) experienciado por Martha em relação ao androide Ash: este lhe gera atração, em razão de sua semelhança quase perfeita com o falecido esposo e, ao mesmo tempo, repulsão, pois as expectativas de Martha sobre como o androide Ash deveria agir não se realizavam, ou se realizavam de modo incompleto e grotesco.

Para Lemos (2018), o problema de Ash não foi ser "falso", mas sim "incompleto", o que pode ter relação com os diferentes papeis que desempenhamos socialmente, que faz o contraste dos rastros digitais que deram origem ao Ash androide, com o Ash "original" que faleceu. Certamente, nessa transposição, algo da história de Ash ficou de fora, fazendo com que sua expressão como androide fosse incompleta perante Martha - a performance algorítmica e a performance corpórea de Ash não coincidem, nem poderão, embora o produto seja vendido como a mais completa e original cópia do seu ente querido que está morto.

Nos parece, portanto, que a trama se encaminha para trazer ao centro uma certa "necessidade" de humanidade, nos padrões definidos pelos preceitos humanistas que vimos elencados ao longo do texto, de modo a reforçar uma visão antropocêntrica que os seres humanos estendem a qualquer tipo de alteridade não humana. Parece, ainda, ser um "problema insolúvel" o fato de, como vimos com Capucci (2010), os androides não expressarem a corporeidade humana, e com Harari (2016), que ainda não se tem notícia de algoritmos que expressam subjetividade. Ou seja, parece só ser válida a interação humana 
com os androides caso estes se pareçam ao máximo conosco, não apenas em termos físicos (porque isso tem um limite, como vimos com a teoria do Uncanny Valley), mas em termos de complexidade subjetiva (emocional, cognitiva). Podemos reconhecer nisso uma demonstração da nossa pretensão racional, herdada dos pilares da modernidade, de recobrir cada espaço da existência com entendimento e clareza, deixando para fora incertezas, caos e estranheza.

No fim das contas, o androide Ash não deixa de ser o que é por definição um androide, como vimos com Maciel (2007) e Oliveira (2003): um robô ou um autômato com feições humanas. Em consonância, também o é manifestação de uma Inteligência Artificial por excelência, como vimos com Russell e Norving (2013) e Camargo (2014), enquanto um agente que executa funções mentais e realiza ações semelhantemente a um ser humano.

O salto qualitativo para um status mais complexo que poderia o tornar "mais humano", ele não foi capaz de fazer. No caso, seus fabricantes não o foram. O androide Ash é uma simulação das interações de Ash quando em vida. Ou seja, a perspectiva pós-humanística não se trata da superação da condição humana, mas de seu desenvolvimento, sendo este necessariamente vinculado aos interesses capitalistas de oferecer produtos conforme as demandas, de ler a realidade como algo passível de ser codificado integralmente em ofertas de serviços e bens, a fim de nos distanciar de nossa condição falível, limitada e em direção à morte. Parece que vivemos intensamente os efeitos da modernidade, e é preciso pensar até que ponto fomos além disso, quer dizer, será que chegamos a ser "pós" qualquer coisa (humanos, modernos)?

\section{Considerações finais}

Diante do que foi discutido neste artigo, percebemos a pertinência de se refletir acerca das transformações tecnológicas e suas incidências nos modos de ser e viver humanos, na atualidade hipercapitalista, consumista, individualista e hipertecnológica. Buonanno (2014) destaca a importância das narrativas como formas organizadas de representação de nossas experiências no mundo, de modo que emocional e cognitivamente, nos ajuda a atribuir significado ao vivido, no nível pessoal e coletivo, no que diz respeito à nossa realidade social. 
Um primeiro aspecto a se destacar é que a discussão aqui realizada abre precedentes para se afirmar que subjetividade e cognição não são sinônimas. Esse é um aspecto muito importante, pois a tendência da biologia no século XXI é a redução da subjetividade às conexões neuronais. No episódio Be right back, o androide consegue replicar com muita precisão, quanto mais interage com Martha e com os dados disponíveis de Ash online, esse aspecto cognitivo, através de sua capacidade de conversar, de dar respostas adequadas às circunstâncias, de interagir com humor. No entanto, permanece um enorme incômodo por parte da protagonista Martha em relação ao androide Ash. Esse "algo" que ela notou que faltava a este remete à ordem da complexidade da subjetividade. Portanto, é uma discussão que se pode empreender em outras pesquisas.

O segundo aspecto que destacamos é sobre o estatuto da inclusão dos não humanos na convivência e socialização humanas. Essa interrogação é prerrogativa para as discussões já iniciadas acerca dos direitos dos ciborgues e os aspectos éticos envolvidos nas relações entre os seres pós-humanos e os humanos (CYBORG FOUNDATION, 2018). Conforme analisado no episódio Be right back, há um conflito ético presente na personagem da filha de Martha e Ash: mantém a convivência com o androide, mas o mesmo, adquirido como produto, permanece nesse status. Como um "brinquedo", mais "evoluído", que fica armazenado no sótão da casa, e cujo reconhecimento de sua existência depende de alguém que o veja, que interaja com o mesmo. Por outro lado, apontar isso de forma dramática - mostrar o personagem "abandonado", no escuro do sótão - revela uma necessidade de humanização emocional dos não humanos, o que é plausível, considerando a hipótese de Mori (2012), quando a aparência dos robôs humanoides, por mais bem feita que seja, não é suficiente para causar empatia. Podemos considerar, portanto, que o imaginário social evocado pelo episódio acerca da nossa reação frente aos androides é povoado pelo desejo de humanização, como única via possível de sociabilidade com não humanos - sua alteridade é demasiadamente insuportável.

O último aspecto que pode vir a ser investigado em outros trabaIhos é a relação entre subjetividade e inteligência artificial. Essa temática já é amplamente explorada pelas produções cinematográficas, mas ainda de modo incipiente na academia e pelos desenvolvedores dessas 
tecnologias na atualidade. Na série Black Mirror, o androide Ash não sofreu com a situação de "abandono": não há emoções mais complexas e primitivas como a busca por amor, por reconhecimento e acolhimento afetivo. Um aspecto que nas frentes de pesquisa e linhas tecnológicas de produção parece ser um grande interesse, em superar e produzir androides dotados de subjetividade.

Por fim, reconhecemos o potencial reflexivo e crítico que guarda as produções midiáticas; ainda que fictícias, nos dão indícios que dialogam historicamente com a ciência e as frentes tecnológicas de produção, dos caminhos percorridos pelos humanos até então e suas possíveis repercussões, através de uma estética e uma linguagem envolventes e impactantes.

\section{REFERÊNCIAS}

ABBAGNANO, Nicola. Humanismo. In: ABBAGNANO, Nicola. Dicionário de Filosofia. 5. ed. São Paulo: Martins Fontes, 2007, p. 518-519.

AMARAL, Adriana. Uma breve introdução à subcultura cyberpunk: estilo, alteridade, transformações e hibridismo na cibercultura. E-Compós, Brasilia, v. 3, p. 1-22, 2005. https://doi.org/10.30962/ec.36.

ANDRADE, William; VIEIRA, Milton; FIALHO, Francisco. Design de animação no fundo do abismo: fotorrealismo e o Uncanny Valley. Tríades - Transversalidades, Design e Linguagens, Rio de Janeiro, v. 4, n. 1, p. 1-15, set. 2015.

AZAMBUJA, Patricia; PERRI, Cecilia. Filosofia e distopia seriadas: sobre Black Mirror e suas relações entre humanos e técnicas. Revista Ícone, Recife, v. 16, n. 1, p. 42-57, 2018.

AZUBEL, Larissa Lauffer Reinhardt. Análise fílmico-compreensiva da narrativa seriada: uma proposta metodológica para ler o imaginário em séries de TV. Revista GEMInIS, São Carlos, v. 9, n. 2, p. 29-45, nov. 2018. https://doi.org/10.4322/2179-1465.013.

BROOKER, Charlie; HARRIS, Owen; REISZ, Barney. Black Mirror. Be right back. $2^{\mathrm{a}}$ temp.; $1^{\circ} \mathrm{epi}$. Direção: Owen Harris. Escrito por: Charlie Brooker. Produtor: Barney Reisz. 2013b. 48 min, son., col. Reino Unido. Série exibida pela Netflix. Acesso em: 14 set. 2017.

BUONANNO, Milly. Narrativas midiáticas no mundo contemporâneo. Entrevista realizada por Monica Martinez. Tríade: Comunicação, Cultura e Mídia, Sorocaba, v. 2, n. 4, p. 200-216, dez. 2014. Disponível em: http://periodicos.uniso.br/ojs/index.php/triade/article/view/2107. Acesso em: 09 mar. 2021.

CAMARGO, Eduardo. Resenha da obra de: TEIXEIRA, João de Fernandes. O cérebro e o robô: inteligência artificial, biotecnologia e a nova ética. São Paulo: Paulus, 2015. Teccogs: Revista Digital de Tecnologias Cognitivas, São Paulo, n. 10, p. 164-172, jul./dez. 2014. 
CAPUCCI, Pier Luigi. A inteligência do corpo: a sua evolução e a sua hereditariedade. Tecnologias do vivente. In: FELICE, Massimo Di \& PIREDDU, Mario (orgs.). Pós-humanismo: as relações entre o humano e a técnica na época das redes. São Caetano do Sul, SP: Difusão Editora, 2010, p. 251-267.

CICERO, Antonio. O ser humano e o pós-humano. In: NOVAES, Adauto (org.). A condição humana: as aventuras do homem em tempos de mutações. Rio de Janeiro: Agir; São Paulo: Edições SESC SP, 2009, p. 263-287.

CYBORG FOUNDATION. Cyborg Rights. Disponível em: https://www.cyborgfoundation.com/. Acesso em: 15 abr. 2018.

ESTEVE, Jessica. V. Representaciones de los medios de comunicación y las tecnologías en las sociedades ficticas de "Black Mirror": un enfoque postmoderno. 2018. Monografia (Conclusão de curso) - Facultat de Ciències de la Comunicació, Comunicació Audiovisual, Universitat Autónoma de Barcelona, Barcelona, 2018.

GUNKEL, David J. (2017). Comunicação e inteligência artificial: novos desafios e oportunidades para a pesquisa em comunicação. Galáxia, São Paulo, n. 34, p. 05-19, jan./abr. 2017.

GRIMAUD, Emannuel. O animismo tecnológico. In: PARÉ, Zaven. Máquinas (1999-2009). Rio de Janeiro: 7 letras, 2009.

HARARI, Yuval Noah. Homo Deus: uma breve história do amanhã. São Paulo: Companhia das Letras, 2016.

HARAWAY, Donna. Manifesto ciborgue: ciência, tecnologia e feminismo-socialista no final do século $X X$. In: TADEU, Tomaz (org.). Antropologia do ciborgue: as vertigens do pós-humano. 2. ed. Belo Horizonte: Autêntica Editora, 2009, p. 33-118.

KUNZRU, Hari. Genealogia do ciborgue. In: TADEU, Tomaz (org.). Antropologia do ciborgue: as vertigens do pós-humano. 2. ed. Belo Horizonte: Autêntica Editora, 2009, p. 119-126.

LEFFA, Vilson J. Vygotsky e o ciborgue. In: SCHETTINI, Rosemary H.; DAMIANOVIC, Maria Cristina; HAWI, Mona M. \& SZUNDY, Paula Tatianne C. (orgs.). Vygotsky: uma revisita no início do século XXI. São Paulo: Andross Editora, 2009, s. p.

LEMOS, Andre. Isso (não) é muito Black Mirror: passado, presente e futuro das tecnologias de comunicação e informação. Salvador: EDUFBA, 2018.

MACIEL, Mario L. B. Ciência ou ficção: robôs e andróides invadem a mente dos humanos. In: ENCONTRO NACIONAL DA ASSOCIAÇÃO NACIONAL DE PESQUISADORES DE ARTES PLÁSTICAS, 16, 2007. Anais [...]. Florianópolis: ANPAP, 2007.

MARCHESINI, Roberto. Contra a pureza essencialista, rumo a novos modelos de existência. In: FELICE, Massimo Di; PIREDDU, Mario (orgs.). Pós-humanismo: as relações entre o humano e a técnica na época das redes. São Caetano do Sul, SP: Difusão Editora, 2010, p. 163-183.

MARCONDES, Danilo. Iniciação à História da Filosofia: dos pré-socráticos a Wittgenstein. 13. ed. Rio de Janeiro: Jorge Zahar, 2008.

MORI, Mashiro. The Uncanny Valley (Translated by Karl F. MacDorman and Norri Kageki). IEEE Robotics \& Automation Magazine, Ixelles, v. 19, n. 2, jun. 2012.

NEGASTERANI, Reza. $\mathbf{O}$ trabalho do Inumano. Tradução de Jean-Pierre Caron. Rio de Janeiro: Zazie edições, 2020. 
OLIVEIRA, Fátima Regis. Ficção Científica: uma narrativa da subjetividade homem-máquina. Contracampo, Niterói, n. 9, p. 177-198, 2003.

ROSA, António Machuco. O destino pós-humano em Stelarc e Masahiro Mori. In: PIRES, Helena; CURADO, Manuel; RIBEIRO, Fábio; ANDRADE, Pedro (coords.). Cibercultura: circum-navegações em redes transculturais de conhecimento, arquivos e pensamento. Edições Húmus: Ribeirão, Portugal, 2018, p. 57-72.

RUSSELL, Stuart J.\& NORVIG, Peter. Inteligência artificial. 3. ed. Rio de Janeiro: Elsevier, 2003.

SAFATLE, Vladimir. Sobre a potência política do inumano: retornar à crítica ao humanismo. In: NOVAES, Adauto (org.). A condição humana: as aventuras do homem em tempos de mutações. Rio de Janeiro: Agir; São Paulo: Edições SESC SP, 2009, p. 199-220.

SANTAELLA, Lúcia. Culturas e artes do pós-humano: da cultura das mídias à cibercultura. São Paulo: Paulus, 2003.

SANTAELLA, Lúcia. Pós-humano, pós-humanismo e anti-humanismo: discriminações. In: FELICE, Massimo Di \& PIREDDU, Mario (orgs.). Pós-humanismo: as relações entre o humano e a técnica na época das redes. São Caetano do Sul, SP: Difusão Editora, 2010, p. 99-143.

SILVA, Antonio de Pádua Dias da. A cidade deteriorada: distopia literária e ecologia na ficção de lgnácio de Loyola Brandão. Terra roxa e outras terras - Revista de Estudos Literários, Londrina, v. 12, p. 5-15, jun. 2008.

UCHOA, Antonio Giovanni Fligliuolo; GODOI, Christiane Kleinübing; MASTELLA, Adriano Silveira. Análise Qualitativa de Material Texto-Audiovisual: por uma metodologia integradora. Atas - Investigação Qualitativa em Ciências Sociais, Lisboa, v. 3, p. 417-422, 2019. Disponível em: https:// proceedings.ciaiq.org/index.php/ciaiq2016/article/view/984/960. Acesso em: 09 mar. 2021.

Recebido em: 20/05/20

Aprovado em: 19/03/21 


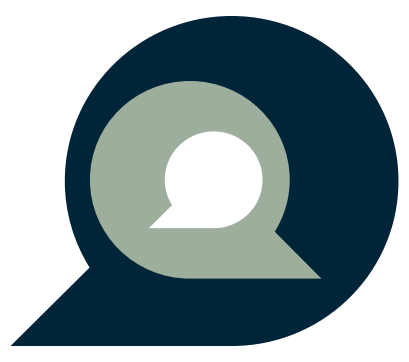

